\title{
La historia conceptual de Koselleck como método de aproximación a la idea de "populismo"1
}

\section{The Conceptual History of Koselleck as a Method of Approaching the Idea of "Populism"}

\author{
Alejandro Sánchez Berrocal ${ }^{2}$ \\ IFS-CSIC y UNED (España)
}

Recibido: 29-06-19

Aprobado: 09-07-20

\section{Resumen}

En este artículo se pretende elaborar una aproximación conceptual al fenómeno del populismo en su variante española. Nuestra hipótesis es que una idea de límites tan borrosos, significados oscuros e incluso sentidos contradictorios como la de "populismo" puede adquirir una mayor claridad y distinción cuando se la analiza desde las categorías del teórico de la historia alemán: "espacio de experiencia", "horizonte de expectativas", "conceptos de acción y movimiento", entre otras. Para ello, abordaremos un análisis de la cuestión desde diferentes planos: semántico, fenoménico y el propiamente conceptual, tomando como materia de investigación las diferentes interpretaciones sobre el populismo, sus contenidos prácticos y teóricos, así como las ideas contenidas en algunos de sus textos y documentos fundacionales.

Palabras-clave: Populismo, Crisis, Historia Conceptual, Koselleck.

\footnotetext{
${ }^{1}$ Este artículo es posible gracias a un contrato FPU (17/03632) del Ministerio de Educación, Cultura y Deporte y se enmarca en las actividades del Proyecto PAIDESOC (FFI2017-82535-P) "El desván de la razón: Cultivo de las pasiones, identidades éticas y sociedades digitales".

2 (alejandro.sanchez@cchs.csic.es) Graduado en Filosofía por la UCM y Máster en Filosofía Teórica y Práctica por la UNED. Actualmente es investigador FPU en el Instituto de Filosofía del CSIC, miembro del Grupo Theoria cum Praxi y doctorando en Filosofía en la UNED.

ORCID: https://orcid.org/0000-0002-9763-3474.
} 


\begin{abstract}
This article aims to develop a conceptual approach to the phenomenon of populism in its Spanish variant. Our hypothesis is that an idea of such blurred boundaries, obscure meanings and even contradictory definitions such as "populism" can acquire greater clarity and distinction when analyzed from the categories of the German theorist of history: "space of experience", "Horizon of expectations", "concepts of action and movement", among others. For this, we will approach an analysis of the issue from different levels: semantic, phenomenonal and strictly conceptual, taking as a research subject the different interpretations about populism, its practical and theoretical contents, as well as the ideas contained in some of its texts and foundational documents.
\end{abstract}

Key-words: Populism, Crisis, Conceptual History, Koselleck.

\title{
1. Introducción
}

La caída del muro de Berlín y el derrumbe de la Unión Soviética inspiraron la ilusoria tesis pseudohegeliana del fin de la historia enunciada por Francis Fukuyama de forma definitiva en 1992. El escenario "postpolítico" entonces abierto, caracterizado por el así llamado "fin de las ideologías" consistente en la progresiva ecualización entre izquierda y derecha habría llegado a su fin en nuestros días tras la irrupción de los neopopulismos ${ }^{3}$. La omnipresencia del concepto en los debates intelectuales y mediáticos, así como su amplia extensión geográfica como experiencia política a lo largo de todo el viejo continente y otras áreas del mundo (Grecia, España, Italia, Hungría, Polonia, Estados Unidos, etc.) confirma que ha dejado de ser un fenómeno singular con raíces en contextos históricos tan concretos como la Rusia zarista o algunos países iberoamericanos para, en cambio, devenir una de las nociones más célebres y al mismo tiempo volubles de la semántica social de nuestro tiempo, la cual ha causado un cortocircuito en el statu quo ideológico de las democracias liberales y ha transformado el modo de entender los escenarios políticos del presente ${ }^{4}$.

Con el objetivo de ilustrar la problematicidad interna y disputa semántica que atraviesa la idea, pero también confiando en que conseguiremos arrojar algo de luz sobre su naturaleza, quisiéramos llevar a cabo una valoración del populismo español desde el plano de la historia conceptual teorizada por Reinhart

\footnotetext{
${ }^{3}$ Usamos la fórmula neopopulismo, tal y como hace con buen criterio Raffaele Sciortino (2019), para diferenciar el populismo contemporáneo, surgido principalmente a partir de la crisis económica y social del 2008, de los populismos históricos: el People's Party estadounidense, los naródniki rusos en el siglo XIX y las sucesivas oleadas de populismo en Iberoamérica a lo largo del siglo XX.

${ }^{4}$ Para profundizar en esta idea véase el excelente ensayo de Carlo Formenti (2016) que referenciamos en la bibliografía.
}

Araucaria. Revista Iberoamericana de Filosofia, Politica, Humanidades y Relaciones Internacionales, año $22, \mathrm{n}^{\circ} 44$. Segundo semestre de 2020. Pp. 155-176. ISSN 1575-6823 e-ISSN 2340-2199 https://dx.doi.org/10.12795/araucaria.2020.i44.07 
Koselleck (1923-2006) y sus principales categorías (espacio de experiencia, horizonte de expectativas, conceptos como índice y factor de cambio, etc.). Previamente, realizaremos un par de breves aproximaciones a la idea populista a modo de introducción general: desde un plano meramente semántico sobre la noción (la "idea" de populismo) y desde otro fenoménico (las "experiencias" políticas -en cuanto a retórica, ideología y actitudes- de partidos políticos y gobiernos realmente existentes). Desde ambas aproximaciones daremos el paso a un análisis más esencial de la idea de populismo, gracias a las categorías de la historia conceptual.

\section{El "momento populista" y las dificultades del concepto: cuestiones semánticas}

Si desde la perspectiva de un autor como Wiles (1970: 204) se señala al respecto de la ideología populista que "toda tentativa por definirla suscita escarnio y hostilidad", las posibilidades de alcanzar una definición, o acaso una tipología general, se advierten más que difíciles. Con menos pesimismo, Bueno Romero (2013: 115) nos presenta así la ambigüedad intrínseca que concierne a la idea del populismo:

Sobre el populismo ha operado una lógica de uso que lo estira conceptualmente, haciéndolo un comodín o una categoría de múltiples contenidos que los autores aprovechan para explicar diversas realidades de países y gobiernos por disímiles que estos sean. Queda al descubierto que académicos e investigadores, a fin de probar la hipótesis sobre la presencia del populismo, critican despectivamente programas de gobierno y el desempeño de líderes en contacto con el pueblo; han configurado, desfigurado y reconfigurado habeas teóricos que aumentan o restringen la capacidad explicativa según la conveniencia argumentativa, y fuerzan las realidades para adaptarlas a un concepto como si este fuera lo suficientemente claro, cuando no lo es.

Esta cita nos pone sobre la pista de lo escurridizo de un concepto como populismo, el cual acepta tantos usos como corrientes teóricas estén dispuestas a utilizarlo. No es que la idea esté "falta de contenido", sino todo lo contrario: acoge en sí tantas determinaciones que pierde, en muchos casos, cualquier delimitación gnoseológica hasta el punto de ser una palabra que sirve para todo (desde el elogio al insulto) y, en cuanto "significante vacío", puede acabar resultando inoperante para el análisis filosófico. No es de extrañar, por tanto, que un autor haya dicho que "[el populismo] generalmente se aplica a un estilo más que a un contenido, declinable y adaptable a las más diversas circunstancias" (Savarino, 2006: 78). 
En términos similares se ha expresado el filósofo esloveno Slavoj Žižek cuando dice que "populism is not a specific political movement, but the political at its purest - the "inflection" of the social space that can affect any political content. Its elements are purely formal, «trascendental», not ontic" (Žižek, 2006: 553). La definición de populismo, por tanto, trata más bien "of a form rather than of a content", como ha indicado Jespersen (2017: 248). El populismo, entonces, sería trascendental en cuanto no está de antemano determinado por unos u otros contenidos específicos. Su carácter camaleónico y voluble le hace sentirse cómodo en discursos y prácticas tan diversas como la xenofobia, el anticomunismo, la tecnocracia, el independentismo, etc. Sin embargo, aunque el populismo sea "difícil de atrapar", es posible inferir una serie de rasgos comunes en las experiencias populistas más allá de sus diferencias particulares.

\subsection{Diez notas a propósito del populismo como "fenómeno" político}

1. El populismo no niega la democracia, sino que la presupone: surge en ellas como una modificación (a modo de "reverso oscuro" o "degeneración", dirían sus opositores) que, en muchas ocasiones, pide precisamente "más democracia". En este sentido, el populismo se acerca a la idea de demagogia que expuso Aristóteles en su Política, una forma corrupta de la democracia donde impera el "capricho de los muchos", cuyas pasiones y sentimientos marcan el itinerario político de aquellos demagogos que funcionan a modo de "aduladores del pueblo". Como parte del repertorio de los demagogos encontramos las promesas irrealizables, el discurso maniqueo o las políticas cortoplacistas que terminan causando problemas de mayor gravedad que aquellos que se pretendían solucionar.

2. La antipolítica, entendida como un discurso que pone en duda o niega el éxito de los partidos políticos y las instituciones gubernamentales. Los líderes populistas se presentan a sí mismos como surgidos "al margen del Sistema", frente a un establishment anquilosado y codicioso que solo piensa en su propio beneficio. Como el cínico consejo atribuido a Franco ("usted haga como yo y no se meta en política"), los líderes populistas "no se meten en política", sino que se presentan como agentes dinamizadores y renovadores del escenario social "más allá de las ideologías" y de la coyuntura política vigente. En un valioso artículo sobre el populismo de Berlusconi firmado por Jorge del Palacio Martín (2017: 243), leemos frases pronunciadas por Il Cavaliere como "no hago, no he hecho, ni haré jamás nada que sea motivado puramente por razones de profesionalismo político o de partido"; "soy simple, no conozco la política con sus trampas y sus arabescos"; "os digo que es posible terminar con una política de chácharas incomprensibles, de disputas estúpidas y de politicastros sin oficio". 
3. La polarización extrema del escenario político que termina por suprimir el valor de diversas organizaciones e instituciones intermedias, tanto a nivel de partido -creándose un vacío entre el líder y sus seguidores- como de gobierno -favoreciendo y concentrando los poderes ejecutivos-. Cuando esta retórica se agudiza hasta sus máximas consecuencias se llega a presentar la distinción entre "amigo y enemigo" (según la célebre fórmula de Schmitt) como esencia última de la política. Este reduccionismo puede darse de muy distintas maneras: "los de aquí" vs. "los de fuera"; "la gente decente" vs. "la casta"; etc., pero siempre suprimiendo cualquier distinción dentro de los grupos antagónicos que, como bloques homogéneos, trazan el "campo de batalla" político.

4. Dentro de este esquema de la polarización extrema y la dialéctica amigoenemigo existe un sujeto colectivo moral que es virtuoso y puro, "el pueblo", por ejemplo, al que los populistas dicen representar frente a los intereses de una oligarquía corrupta, "la casta", como hemos oído los últimos años en España. De este modo, lo que sucede es que frente a un "nosotros" existe siempre un "ellos" donde se juega una especie de batalla definitiva entre el Bien y el Mal cargada de contenidos maniqueos y un marcado tono teológico-político.

5. El sistema político vigente, afectado por una supuesta o real "crisis orgánica", es puesto en duda en su totalidad, frente al cual se postula un pasado mítico al que volver ("la Francia soberana" de Le Pen, "la gran América" de Trump) o un futuro iluminador ("la patria socialista", "el país para la gente decente"). Se producen, por tanto, operaciones teóricas de desplazamiento de la realidad efectiva para situarla en un tiempo que, gracias a la "esperanza" de un pueblo y a la determinación de sus líderes populistas, llegará tarde o temprano.

6. La existencia de un liderazgo carismático cercano al caudillaje o al paternalismo donde un líder se presenta como el guía del pueblo, capaz de entender sus demandas y necesidades mejor que otras organizaciones políticas ${ }^{5}$. En este sentido, el liderazgo populista sería un caso extremo del "personalismo político": los ciudadanos no se relacionan con el espacio público a través del partido, ni mucho menos atendiendo a los programas electorales, sino a través de la adhesión a un líder carismático capaz de guiarlos sin más mediaciones.

7. El desprecio por los elementos mediadores y los sistemas de contrapeso de las democracias liberales como los partidos, sus listas cerradas, las elecciones cada un número determinado de años, etc. En su lugar, estos cauces tradicionales de acción política se sustituyen por asambleas populares, democracia directa y referéndums, en los cuales se haría oír la "voz del pueblo", su "voluntad", sustancia última de decisión. Vox populi, vox Dei, afirma el populista, considerando la "opinión popular" (hoy situada en los social media) una instancia pura e infalible que nunca se equivoca.

${ }^{5}$ Siguen vigentes los análisis a propósito de esta cuestión realizados por Max Weber (1994: 193195) en su monumental obra Economía y Sociedad.

Araucaria. Revista Iberoamericana de Filosofia, Política, Humanidades y Relaciones Internacionales, año $22, \mathrm{n}^{\circ} 44$. Segundo semestre de 2020. Pp. 155-176. ISSN 1575-6823 e-ISSN 2340-2199 https://dx.doi.org/10.12795/araucaria.2020.i44.07 
8. La retórica "soberanista" o, en ocasiones, nacionalista que crea, partiendo de la división interna amigo-enemigo, una dialéctica internacional contra un enemigo externo que amenaza a la patria: "los comunistas", "los burócratas de Bruselas", "los inmigrantes". El populismo, por tanto, tiene en cuenta las relaciones internacionales y el enfrentamiento entre Estados a una escala internacional, de ahí que, precisamente, opte por retóricas beligerantes (contra el "tío Sam", por ejemplo), autárquicas (frente a la globalización económica, si se quiere) o de alianza frente a terceros ("los países del norte de Europa contra los perezosos mediterráneos").

9. El discurso del populismo es marcadamente ambiguo y se alimenta, en ocasiones, de teorías conspirativas de escasa comprobación empírica. Como estilo político, el populismo es esencialmente equívoco: a la vez que sienta distinciones tajantes y reduccionistas ofrece, también, un repertorio de diagnósticos y soluciones que resulta turbio e indeterminado. Además, el discurso populista puede transformarse -en cuestión de semanas- hasta "traicionar" las posiciones ideológicas de partida. Esto es así porque, como veíamos más arriba, el populismo es más un "estilo" o una "forma" virtualmente abierta a contenidos muy diversos que, por si esto fuera poco, debe tener un alcance "total" (pues teóricamente el sujeto representado es "el pueblo" mismo) $\mathrm{y}$, por tanto, fácilmente adaptable a situaciones políticas y clases sociales muy diversas. Las concepciones del mundo y los programas políticos sustantivos se vaporizan o pierden su relevancia clásica, lo que desplaza el populismo a posturas implícitamente nihilistas ${ }^{6}$.

10. El adanismo, entendido como una división de la historia nacional o internacional a través de un corte sin solución de continuidad que contrapone un pasado oscuro y pobre ("el Régimen del 78", "la década perdida") con un futuro esperanzador y armónico ("la España de la gente decente", "la América grande de nuevo") o, invirtiendo los términos, un futuro apocalíptico ("la Francia islámica") a un pasado memorable ("los treinta gloriosos").

\section{Populismo e historia conceptual}

Más arriba hemos visto la problematicidad interna de la que se ve afectada la idea de populismo, la cual constantemente rebasa las categorías de la sociología o la ciencia política para remitir a cuestiones (democracia, soberanía, Estado, etcétera) de cuño filosófico. Creemos que el conjunto de rasgos y características que hemos recogido $-\mathrm{y}$ que de ahora en adelante utilizaremos, junto a nuevos

\footnotetext{
${ }^{6}$ Solo podemos sugerir aquí el eventual rendimiento de una interpretación de las corrientes intelectuales que inspiran el populismo posmoderno de nuestros días desde tesis críticas similares a las que sostuvo Lukács (1976) en sus análisis de las tendencias irracionalistas de la filosofía contemporánea.
} 
hallazgos empíricos, como materia prima de nuestra investigación filosóficamerece ser potenciado con una lectura del populismo desde las herramientas que ofrece la historia conceptual (Begriffsgeschichte) de Reinhart Koselleck (1923-2006), cuyo pensamiento ayuda a comprender la permanencia, cambio y novedad de las nociones que componen nuestra semántica social y, concretamente, la irrupción de nuevos lenguajes políticos y filosóficos que son el reflejo de un cambio en las experiencias históricas.

\subsection{Crisis y Sattelzeit ... ¿hoy?}

La historia conceptual de Koselleck insiste en la mutua influencia de dos esferas del acontecer histórico: las profundas transformaciones políticas y sociales y el nuevo mundo intelectual que las acompaña. Semejante interacción supone que tanto las nuevas experiencias históricas obligan a modificar, resignificar y desechar determinados aparatos conceptuales heredados de la tradición, como también el nuevo ámbito semántico e intelectual debe arrojar luces e incluso guiar la diagnosis y prognosis de los tiempos pasados, presentes y futuros. De este modo lo resume Gómez Ramos (Koselleck, 2004: 16) cuando afirma: "La historia no puede prescindir de una delimitación conceptual de la época [...] Debe analizar cómo la entrada en acción de los conceptos, su uso, provoca unas transformaciones estructurales que afectan tanto a la sociedad como al concepto mismo". En este juego de mutuas transferencias, desplazamientos y anticipaciones entre la praxis y la semántica, se configura la historia conceptual.

Si hubiera que nombrar una noción privilegiada en el marco de la reflexión teórica de Koselleck esta sería la de Sattelzeit, un "Tiempo-Bisagra" que ocupa el lugar de supuesto fundamental como guía de una labor que busca esclarecer la autoconciencia y comprensión lingüística del mundo moderno. Según el teórico de la historia alemán, la especificidad del Sattelzeit es irreductible a cualquier otra época histórica y supone una "relación cambiante con la naturaleza y la historia, con el mundo y con el tiempo, en pocas palabras; el comienzo de la Modernidad". Lo que caracteriza a este "Tiempo Nuevo" (Neuzeit) que se abre durante el Sattelzeit es el surgimiento de palabras, conceptos y significados originales como consecuencia de una experiencia y autocomprensión de la situación histórica absolutamente novedosas, cifradas en el acelerado cambio de los vínculos entre el "espacio de experiencia" (Erfahrungsraum) y el "horizonte de expectativas" (Erwartungshorizont).

No es tema de este artículo extendernos en la caracterización del Sattelzeit, pues solo recurrimos a él en cuanto paradigma de un tiempo de grandes transformaciones en la historia y semántica social. Tampoco nos parece prudente considerar de forma definitiva, desde el presente en marcha, que el 
tiempo actual sea una especie de Sattelzeit posmoderno donde la tradición heredada y el futuro previsto se configuran de una manera radicalmente original, sin perjuicio de las sugestivas vías de investigación que ello pueda contener ${ }^{7}$. En realidad, nos proponemos algo más sencillo: ofrecer una aproximación filosófica a la idea de populismo desde la historia conceptual de Koselleck. Para ello, queremos hacer uso de cuatro nociones fundamentales en el aparato teórico del autor alemán, las ya citadas "espacio de experiencia" y "horizonte de expectativas" y, también, las consideraciones a propósito de los conceptos como "indicadores" y "factores" del cambio político, social e histórico.

\title{
3.2. Historia conceptual
}

Una primera advertencia que podría hacerse a propósito de la historia conceptual que propone Koselleck es que ella no es historia del lenguaje, ni tampoco un mero "rastreo" de nociones y términos a lo largo de un determinado espacio temporal. Por el contrario, de lo que se trata es de aprehender aquellos conceptos sociales y políticos fundamentales que alcanzan una relevancia histórica tal que devienen conceptos metahistóricos, esto es, ideas eminentemente filosóficas. Esta reflexión de segundo grado en que consiste la historia conceptual evita, además, una posible trampa interpretativa de la labor teórica de Koselleck: no se trataría, ni mucho menos, de exponer y describir la semántica de un periodo histórico de modo autotransparente, como si la historia conceptual fuera la demostración del "Espíritu de mundo" en una determinada época, sino precisamente de sacar a la luz las contradicciones internas, en el proceso mismo del devenir histórico, de ciertos conceptos, corrientes teóricas y grupos políticos implicados, lo que impide una identificación total entre historia social e historia conceptual $\mathrm{o}$, mejor dicho, entre los procesos sociales y políticos de la historia efectual y su enunciación lingüística. De este modo lo expresa el teórico alemán cuando dice:

\begin{abstract}
Al liberar a los conceptos en el segundo paso de una investigación, de su contexto situacional y al seguir sus significados a través del curso del tiempo para coordinarlos, los análisis históricos particulares de un concepto se acumulan en una historia del concepto. Únicamente en este plano se eleva el método históricofilológico a historia conceptual, únicamente en este plano la historia conceptual pierde su carácter subsidiario de la historia social (Koselleck, 1993: 113).
\end{abstract}

\footnotetext{
${ }^{7}$ Acaso su uso pueda extenderse, de manera heterodoxa y aunque sea por analogía, a otras épocas históricas. Un artículo de David Soto Carrasco (2015: 547) sobre crisis y populismo en España inicia sus reflexiones precisamente recurriendo a la noción Sattelzeit: "La explosión de la crisis económica y financiera de 2008 y su desarrollo en los últimos años ha provocado una serie de cambios políticos y culturales que nos hacen intuir que estamos ante un nuevo tiempo histórico o al menos, tal y como se desprende de la aceleración de los acontecimientos, ante un tiempo-gozne, una sattelzeit, un tiempo máximamente crítico en el sentido de que nos hablaba Koselleck”.
} 
La premisa metodológica que invita a abstraer los conceptos de sus situaciones particulares para hacer de ellos objetos de una reflexión metahistórica es aquello que imprime el carácter filosófico en la historia conceptual. Por esta razón, queda descartada la posibilidad de que el concepto y la palabra asociada a él sean una y la misma cosa. De lo contrario, toda posibilidad de historia conceptual quedaría cancelada. Sin dejar de ser palabras, los conceptos se elevan en la medida en que, de hecho, no se identifican con ellas. Esto sucede cuando "la totalidad de un contexto de experiencia y significado sociopolítico, en el que se usa y para el que se usa una palabra, pasa a formar parte globalmente de esa única palabra" (Koselleck, 1993: 117). El concepto, por tanto, es un crisol de significados que condensa, a través de un solo significante, un conjunto de experiencias, juicios y relaciones, de carácter teórico y práctico, hasta el punto de acoger dentro de sí una plurivocidad que hace problemática, cuando no imposible, la investigación de una determinada idea sin tener en cuenta su multiplicidad de denominaciones y la heterogeneidad de sus referencias.

Como parte de la historia social, la historia conceptual es precisamente el método que permitiría conciliar estas tensiones entre el concepto y los procesos históricos, sociales y políticos designados. Como nos indica Koselleck (1993: 122), "el método de la historia conceptual es una conditio sine qua non para las cuestiones de la historia social, precisamente porque las palabras que se han mantenido no son, tomadas en sí mismas, un indicio suficiente de estados de cosas" y, continúa el teórico de la historia alemán, "porque -inversamenteestados de cosas que se han modificado a largo plazo se conciben desde expresiones muy diferentes". Esto puede arrojar algunas luces sobre las dificultades intrínsecas para definir el concepto de populismo, atravesado por una problematicidad interna que hace imposible alcanzar un consenso sobre su alcance y significado ${ }^{8}$. Quisiéramos profundizar ahora en estas dificultades y, con la ayuda de las reflexiones de Koselleck, tratar de esclarecer en la medida de lo posible la cuestión.

\subsection{Populismo: tipos de conceptos}

Como señala el teórico de la historia alemán, si nos situamos en una óptica temporal, los conceptos pueden dividirse en tres categorías:

[1.] Se puede tratar de conceptos de la tradición, como los de la teoría aristotélica de la organización, cuyos significados se mantienen parcialmente y cuya pretensión aún se puede hacer efectiva empíricamente en las condiciones actuales [...] [2.] También se pueden clasificar conceptos cuyo contenido se ha transformado tan decisivamente que, a pesar de seguir teniendo los mismos

\footnotetext{
${ }^{8}$ En España, el ensayo de una aproximación conceptual desde las categorías de Koselleck -aunque no solo- se lo debemos a José Luis Villacañas (2015).
}

Araucaria. Revista Iberoamericana de Filosofí, Política, Humanidades y Relaciones Internacionales, año $22, \mathrm{n}^{\circ} 44$. Segundo semestre de 2020. Pp. 155-176. ISSN 1575-6823 e-ISSN 2340-2199 https://dx.doi.org/10.12795/araucaria.2020.i44.07 
significantes, los significados apenas son comparables y sólo se pueden alcanzar históricamente [...] [3.] Finalmente, se pueden clasificar los neologismos que aparecen y que responden a determinadas situaciones políticas o sociales cuya novedad pretenden registrar o incluso provocar (Koselleck, 1993: 115).

En un primer momento, resulta complejo ubicar el populismo de forma concluyente en uno de los grupos de acuerdo con esta tipología conceptual que propone Koselleck. Sin embargo, basta con tener en cuenta que ella no supone un esquema rígido y excluyente, sino que cuenta con diversos niveles donde pueden darse intercalaciones de diverso tipo. Según lo dicho, podríamos aventurar que el concepto "populismo" tiene un difícil encaje en el primer grupo, esto es, como una noción "tradicional" que, desde la Antigüedad a nuestros días, conserva un significado más o menos estable. Esto solo sería posible en el caso de otorgar un radio demasiado amplio al concepto de "populismo" y, a su vez, insertarlo en una trama de analogías y semejanzas con otros como "demagogia" o "tiranía", en sentido estrictamente aristotélico como modos de gobierno "desviados" de una trayectoria "normal": en ellos, el pueblo habría adquirido, de manera anómala, el carácter de un sujeto político enfrentado a las oligarquías decadentes o a una clase política corrupta. Si atendemos al segundo grupo, el "populismo" debe analizarse como un concepto que se ha transformado de tal modo que su manifestación contemporánea tendría poco en común con sus apariciones "históricas". Este sería el caso, por ejemplo, de una consideración del populismo que estableciera una comparación entre el fenómeno actual y los tribunos de la plebe de la República Romana, donde la "masa popular" sería depositaria de la verdadera esencia de la política frente a las élites que la gobiernan. Tanto en el primer como en el segundo caso vemos que pueden sugerirse no pocas semejanzas y rasgos en común entre los populismos "clásicos" y los contemporáneos, pero la aprehensión del concepto no puede realizarse mediante el mero cotejo de afinidades y diferencias. Es por ello que posiblemente el concepto de "populismo" se enmarque en el tercer grupo propuesto por Koselleck, el de "los neologismos que aparecen y que responden a determinadas situaciones políticas o sociales cuya novedad pretenden registrar o incluso provocar" (idem).

Sin perjuicio, insistimos, de las relaciones que puedan establecerse entre las manifestaciones "tradicionales" e "históricas" del populismo con las contemporáneas, una mejor comprensión del fenómeno implica hacerse cargo de su idea desde la última categoría propuesta por Koselleck, donde entran otros conceptos como "comunismo", "liberalismo" o "fascismo". El populismo se incorporaría, así, a una larga lista de "-ismos" que componen lo que en terminología koselleckiana se denominan "conceptos de movimiento y acción". Este tipo de conceptos cuentan con una determinada estructura temporal interna e implican, a su vez, una teoría de la acción. 
Por lo que respecta a la temporalización de estos conceptos, su nota definitoria es lo que Koselleck denomina una "producción compensatoria", que puede resumirse en la siguiente frase: "cuanto menor sea el contenido de experiencia, tanto mayor será la expectativa que se deriva de él" (Koselleck, 1993: 356). Podría decirse que el contenido de experiencia del populismo es escaso o nulo, sin embargo, y precisamente por ello, su forma admite una multiplicidad casi ilimitada de realidades teóricas y sociales ${ }^{9}$. Cuenta con todas las expectativas porque tiene un contenido de experiencia indefinido. Como apenas hay, para el populismo, tradiciones o situaciones históricas en las que asentar sus propuestas, se mira hacia un horizonte donde todas ellas podrán ser realizadas. Esto nos ayuda a comprender, también, que el adjetivo "populista" haya acompañado a nombres que designaban fenómenos políticos tan heterogéneos como el socialismo latinoamericano o la extrema derecha de los países del norte de Europa. Poco o nada tienen en común si se analizan sus contenidos, pero lo comparten todo respecto a su estilo político: una relación profundamente asimétrica entre el espacio de experiencia en que surgen y su horizonte de expectativas. Uno de los teóricos más destacados del populismo español se expresa en estos términos para explicar las tesis de Laclau:

El populismo, entonces, es el estilo discursivo que interpela a los sectores subordinados y excluidos para unificarlos en una construcción bipolar frente al orden existente y las élites rectoras, responsabilizadas de las fallas sociales, una formación que cristaliza necesariamente en "nombres" — el pueblo, de forma destacada el nombre del líder o de una fecha simbólica - puesto que ningún concepto que aludiese a realidades sociológicas exactas podría representar la heterogeneidad radical de la nueva identidad construida (Errejón, 2015: 134).

Anteriormente hemos mencionado sin detenernos en ello dos ideas fundamentales de la reflexión sobre la historia que elabora Koselleck: espacio de experiencia y horizonte de expectativas. Quisiéramos precisar brevemente su significado para continuar analizando el concepto de populismo en cuanto concepto de acción y movimiento.

\subsection{Populismo: espacio de experiencia y horizonte de expectativas; concepto de acción y concepto de movimiento}

El par de categorías "espacio de experiencia" y "horizonte de expectativas" no debe confundirse con unas herramientas auxiliares más o menos valiosas para la metodología histórica, ni mucho menos son, ellas mismas, objeto de la

\footnotetext{
${ }^{9}$ Esto lo prueba que no haya una ideología o un programa político que sea per se populista, ni mucho menos un corpus teórico que sirva de referencia a las experiencias políticas denominadas populistas. Sirva como excepción, acaso, la obra clásica de Laclau (2005), donde podríamos considerar que los planos del diagnóstico y de la prescripción, en ocasiones, se identifican.
}

Araucaria. Revista Iberoamericana de Filosofí, Política, Humanidades y Relaciones Internacionales, año $22, \mathrm{n}^{\circ} 44$. Segundo semestre de 2020. Pp. 155-176. ISSN 1575-6823 e-ISSN 2340-2199 https://dx.doi.org/10.12795/araucaria.2020.i44.07 
reflexión historiográfica. Para Koselleck (1993: 336), ambas categorías son, en realidad, algo mucho más importante: condición de posibilidad de toda historia en cuanto remiten a un dato antropológico universal, como es la relación entre pasado y futuro, entre experiencia y expectativa. La tesis fundamental, por tanto, es que "la experiencia y la expectativa son dos categorías adecuadas para tematizar el tiempo histórico por entrecruzar el pasado y el futuro" y, añade el teórico de la historia alemán: "las categorías son adecuadas para intentar descubrir el tiempo histórico también en el campo de la investigación empírica, pues enriquecidas en su contenido, dirigen las unidades concretas de acción en la ejecución del movimiento social o político" (Koselleck, 1993: 337).

En el caso de la categoría de "espacio de experiencia", se trata de un "pasado presente, cuyos acontecimientos han sido incorporados y pueden ser recordados" (Koselleck, 1993: 338), un espacio donde se reúnen diferentes estratos temporales ya heredados como un todo, sin que ello implique que sea una totalidad rígida dada de antemano: los hechos cristalizados en una experiencia han pasado, pero la revisión, articulación e interpretación de sus razones y consecuencias están desde el presente en continuo ejercicio. Respecto al horizonte de expectativas, este remite a lo que aún no ha sucedido pero, también desde el presente, parece vislumbrarse, es decir, a la intuición de un nuevo espacio de experiencia como posible en un futuro realizable, pero no necesariamente inevitable. "La posibilidad de descubrir el futuro choca, a pesar de los pronósticos posibles, contra un límite absoluto, porque no es posible llegar a experimentarla", nos recuerda Koselleck (1993: 340), quien señala cómo el entrecruzamiento de espacio de experiencia y horizonte de expectativas es siempre de algún modo desigual, como desigual es la relación que una y otra categoría proponen con el pasado y el futuro, cuyo correlato sería la idea de pronóstico: el pronóstico funciona como ejemplo de la conexión entre experiencia y expectativa en la medida en que implica recurrir a un determinado conjunto de experiencias que, no obstante, son deficientes para llegar a deducir la expectativa esperable.

Si regresamos al populismo español y continuamos con su análisis desde estas coordenadas, vemos que su carácter de concepto de movimiento y acción se cifra en el pobre espacio de experiencia que postula frente a la oferta de un horizonte de expectativas extremadamente amplio. Su movimiento se expresa en una manifiesta ambición por el cambio, noción que ha adquirido carta de naturaleza para denominar a las políticas del populismo español. El cambio implica la insatisfacción con un espacio de experiencia que se percibe como caduco e inoperante en cuanto realidad socio-política, lo que algunas de las figuras más destacadas del populismo español han evidenciado, de hecho, con una conocida frase de Gramsci, tal y como hizo Juan Carlos Monedero (2014): "el viejo mundo se muere. El nuevo tarda en aparecer. Y en este claroscuro surgen los monstruos". 
Como respuesta a la crisis generalizada, el populismo español invita al cambio y, con ello, amplía la distancia entre en el espacio de experiencia y el horizonte de expectativas. Es lo que al principio de este artículo denominamos como un rasgo de los populismos, el adanismo, esa operación teórica que consiste en dividir la historia nacional mediante un corte sin solución de continuidad que contrapone un espacio de experiencia profundamente oscuro y que merece ser dejado atrás ("el Régimen del 78") frente a un horizonte de expectativas harto prometedor ("asaltar los cielos"). Más adelante volveremos sobre esta cuestión, por lo que ello implica a las categorías de movimiento y acción.

Acudamos ahora a uno de los textos fundacionales de Podemos, el documento Mover ficha: convertir la indignación en cambio político $(2014)^{10}$, firmado por algunas de sus figuras más representativas como el mismo Juan Carlos Monedero, Rita Maestre o Teresa Rodríguez. En él se afirma abiertamente que "movimientos de indignación política como el $15 \mathrm{M}$ conectaron con una clara voluntad popular", sentando así el discurso de que la incipiente formación política conectaba directamente con la "voluntad popular" que emanó del 15M. Como parte de este discurso, los signatarios del manifiesto señalan que "en las próximas elecciones al Parlamento Europeo [2014] es necesario que haya una candidatura que se ofrezca a la ola de indignación popular que asombró al mundo". Como respuesta al grito que "en las calles se repite insistentemente": "sí se puede", el manifiesto afirma: "nosotras y nosotros decimos: Podemos".

Este espíritu voluntarista que anima la acción política del populismo español es uno de los síntomas que nos permite valorarlo desde las categorías arriba expuestas. ¿Pero cuál es exactamente el espacio de experiencia que pueden cambiar? La transformación propuesta es en cierto modo radical, pues busca "modificar nuestro marco constitucional"11 a la vez que romper con el pasado institucional del país, pues, advierten: "cumplir este programa implica llevar a cabo cambios en la norma del 78". La consideración que lleva a cabo -al menos en su origen- el populismo español de la democracia española iniciada a partir de 1978 no consiste en una enmienda a la totalidad, mas sí en unas modificaciones profundas: no se impugna toda experiencia hasta el momento, pero se pone en duda que buena parte de ella sea deseable para los tiempos futuros. Y, mientras que el espacio de experiencia es, por un lado, pobre en su momento negativo ("régimen del 78") e inexistente como momento institucional (pues no se ha producido un "gobierno populista" realmente decisivo), el horizonte de expectativas está tan saturado de promesas como indefinido en su formulación: "el cielo no se toma por consenso, sino por asalto", afirmó Pablo Iglesias, líder de Podemos, hace unos años.

${ }^{10}$ El manifiesto puede leerse en el siguiente enlace: http://tratarde.org/wp-content/uploads/2014/01/ Manifiesto-Mover-Ficha-enero-de-2014.pdf (última consulta: 20/06/2019).

${ }^{11}$ Esta cita la hemos obtenido del siguiente enlace: https://es.slideshare.net/kidetza1/programaeleccionesgeneralespodemos2015 (última consulta: 20/06/2019).

Araucaria. Revista Iberoamericana de Filosofia, Politica, Humanidades y Relaciones Internacionales, año $22, \mathrm{n}^{\circ} 44$. Segundo semestre de 2020. Pp. 155-176. ISSN 1575-6823 e-ISSN 2340-2199 https://dx.doi.org/10.12795/araucaria.2020.i44.07 
Acaso sea de especial interés profundizar en el diagnóstico que el populismo español hace de su tiempo y en la peculiar relación entre espacio de experiencia y horizonte de expectativas, habida cuenta de la singular importancia que han adquirido las categorías temporales como elementos de semántica política. El movimiento de los Indignados es un buen ejemplo de ello, en gran medida porque su discurso hacía referencia a una ruptura de expectativas (laborales, personales, políticas) causada por la crisis de reproducción del capitalismo tardío. Nos aproximaremos, por tanto, a algunas de las expresiones que un par de plataformas impulsoras del 15-M (Juventud sin futuro y Democracia real $y a)$, germen del populismo español, recogían en sus manifiestos ${ }^{12}$.

Cuando desde Juventud sin futuro se denuncia que la precariedad y los recortes tienen como problema fundamental "la consecuencia más grave y con mayor impacto en el futuro: la juventud más preparada de nuestra historia vivirá peor que sus padres", no hacen más que señalar el desacuerdo con un cierto hiato generacional causado por una precariedad cada vez mayor: no es una u otra política lo que es objeto de descontento, sino el malestar por una percepción temporal de la realidad sociopolítica que, lejos de estar protagonizada por el progreso, implica un empobrecimiento del nivel de vida de las nuevas generaciones, lo que hace que, inevitablemente, el espacio de experiencia sea visto como algo insuficiente e incluso negativo, el cual requiere un horizonte de expectativas radicalmente nuevo.

En el caso del manifiesto de Democracia real ya, se cree también en las posibilidades de una transformación de la situación política, pues "si todos nos unimos, podemos cambiarla", por lo que sostienen que "las prioridades de toda sociedad avanzada ( $\mathrm{sic}$ ) han de ser la igualdad, el progreso, la solidaridad, el libre acceso a la cultura, la sostenibilidad ecológica y el desarrollo, el bienestar y la felicidad de las personas". Estas demandas, a primera vista, resultan bastante vagas, pero es el carácter impreciso e incluso oscuro que adquieren lo que hace de ellas algo eficaz desde el punto de vista del populismo y lo que, para nosotros, resulta atractivo si lo consideramos bajo la óptica de un concepto de movimiento: todas las demandas son tan amplias y generales que cualquier ciudadano podría estar virtualmente de acuerdo con ellas, lo que es, a su vez, un problema conceptual cuando las insertamos en contextos políticos en ocasiones enfrentados entre sí, ya que, por ejemplo, también el capitalismo financiero contra el que protesta Democracia real ya tiene sus ideas sobre la igualdad, el progreso y la solidaridad, si bien a otra escala y posiblemente en sentido contrario. No se trata de que estas ideas sean o no realizables, cuestión que no nos ocupa juzgar a nosotros, sino contradictorias entre sí. De algún modo, el

\footnotetext{
${ }^{12}$ Las citas de ambos manifiestos son extraídas de las versiones: Manifiesto: Juventud sin futuro: https://www.diariodeunjugon.com/manifiesto-juventud-sin-futuro/ (última consulta: 20/06/2019) у Manifiesto: Democracia Real Ya: https://elmanifiesto.com/nacion/3713/manifiesto-democracia-realya.html (última consulta: 20/06/2019).
}

Araucaria. Revista Iberoamericana de Filosofia, Politica, Humanidades y Relaciones Internacionales, año $22, \mathrm{n}^{\circ} 44$. Segundo semestre de 2020. Pp. 155-176. ISSN 1575-6823 e-ISSN 2340-2199 https://dx.doi.org/10.12795/araucaria.2020.i44.07 
movimiento de los Indignados parecía rebasar constantemente las coordenadas políticas para asumir una crítica de tipo ético o cultural ${ }^{13}$.

Como todo concepto de movimiento en sus inicios, el populismo postula una constelación de nociones que remiten a grandes cambios ("progreso", "desarrollo", "bienestar"...) y busca romper con un espacio de experiencia negativo ("régimen del 78") que, sin embargo, no consigue ser sustituido todavía por uno nuevo, el cual queda desplazado, más bien, por las promesas de un horizonte de expectativas capaces de renovar una determinada coyuntura sociopolítica. Hasta que tales promesas se hagan realidad, toda experiencia será de algún modo inauténtica, toda solución que no pase por una profundización en los principios populistas no será una solución per se, sino más bien una expresión diferente del problema. El futuro, siempre abierto, dispone y asegura el escenario donde los populismos pueden hacer énfasis en la redefinición y estructuración de nuevas experiencias y los problemas asociados a ellas, no necesariamente inalterables pero sí irresolubles excepto si el populismo -y solo él- es capaz de darle solución. Mientras el populismo no se realice, cualquier alternativa ajena a sus propuestas es denunciada como "cambio lampedusiano", porque en cuanto concepto de movimiento requiere la exclusión de otros posibles conceptos (otros "-ismos"), tal y como reconoce Koselleck (véase 2012: 158) que sucede con este tipo de nociones: la alusión a una "patria", por ejemplo, implica la exclusión de otras; la agrupación de unos ciudadanos en torno a una "clase" tiene como consecuencia que otros queden fuera de esa idea; el nuevo país que imagina el populismo solo será tal si es él quien se ve implicado en la acción de su reforma.

Pero como todo concepto de movimiento, vive atravesado por una tensión que lo hace ambivalente y frágil, pues su relación con el pasado y el futuro no puede quedar jamás cancelada: una nación puede ir ahondando cada vez más en la supuesta necesidad de soluciones populistas, pero jamás puede llegar a conseguirlas todas, pues concluido el malestar termina también el populismo del que es síntoma. Esta tensión entre "lo institucional" y "lo social" es uno de los principales déficits de la teoría populista. De ahí que resulte oportuna una especie de regla que afirma Koselleck (2012: 38) a propósito de los conceptos de movimiento: "cuanto menores son las experiencias contenidas, mayores son las expectativas". Si este débil equilibrio se rompe y, con esto, la compensación deja de ser tal, si el espacio de experiencia queda saturado, el horizonte de expectativas termina por difuminarse para siempre.

Hasta ahora hemos valorado el populismo como un peculiar concepto de movimiento, pero debemos recordar que también mencionamos más arriba que

${ }^{13}$ En la línea de lo señalado por Boltanski y Chapiello (2002) o Jodi Dean (2018) a propósito de los componentes artísticos y libertarios, en perjuicio de los estrictamente políticos, en las protestas de los nuevos movimientos sociales.

Araucaria. Revista Iberoamericana de Filosofí, Política, Humanidades y Relaciones Internacionales, año $22, \mathrm{n}^{\circ} 44$. Segundo semestre de 2020. Pp. 155-176. ISSN 1575-6823 e-ISSN 2340-2199 https://dx.doi.org/10.12795/araucaria.2020.i44.07 
se trata de un concepto de acción. Como tal rasgo está estrechamente ligado con su carácter de concepto de movimiento, nos será más fácil exponer ahora de qué modo el populismo es un concepto de acción. Veamos primero en qué consisten según Koselleck.

En general, los conceptos de acción son aquellos que implican por sí mismos una teoría de la acción, esto es, cuya estructura está atravesada por una dinamicidad tal que exige de un avance hacia una meta que, situada en un lejano horizonte de expectativas, asegura su recurrencia en el tiempo. La temporalidad, el dinamismo y la necesidad de una praxis abren un determinado espacio de acción. El paradigma sería la idea de Ilustración (aunque puede extenderse a otros conceptos como "democratismo" o "republicanismo"):

La Ilustración no solo es incoactiva e innovadora en relación con los periodos históricos anteriores al pretender concebirse a sí misma como una época que produce cosas nuevas. Ilustración también es un concepto de acción que posee una estructura temporal interna que le es inherente. Con este concepto se crea una tensión que presupone o requiere no solo que haya cambios como antes, sino que estos cambios sean voluntarios y dirigidos en un sentido determinado (Koselleck, 2012: 209).

Si los conceptos de movimiento implicaban una determinada relación entre espacio de experiencia y horizonte de expectativas, los conceptos de acción conservan esta idea pero cuentan, además, con un cierto potencial pragmático. El populismo, como las ideas de emancipación o revolución, abren un futuro que, de algún modo, resulta inédito respecto a un espacio de experiencia incapaz de producir nuevas expectativas: se dirige hacia un fin, se orienta de acuerdo con unos medios y su trayectoria no ha sido antes ensayada por otras formaciones socio-políticas. Por ello, como señala Koselleck (2012: 216), "todos estos conceptos de movimiento tienen en común poseer o generar, como singulares colectivos y de forma análoga a ilustración, una teoría de la acción".

La novedad radical del horizonte de expectativas y la estrechez del espacio de experiencia requieren que la transformación, esto es, la acción, se lleve a cabo de forma inmediata y su realización resulte apremiante. Hasta que ello no suceda, el "estado de cosas" que se quiere denunciar resulta hostil, insufrible y propio de un mundo caduco que aún no termina de desaparecer. Es por eso que la teoría de la acción implícita en todos estos conceptos necesita hacer valer, en el tránsito de las luchas políticas, sus propias experiencias, para lo que resulta imprescindible que actúe como "medio de integración de los ciudadanos" (Koselleck, 2012: 220). Por ello, no es de extrañar que uno de los teóricos del populismo español, Íñigo Errejón (2016) se haya expresado en estos términos: 
En los momentos de crisis, que nunca son de clarificación de bandos sino de fragmentación y colapso de las identificaciones tradicionales, se hace más importante aún la política como construcción colectiva de un relato que agrupe los dolores, postule una visión diferente de la situación y proponga un horizonte y aspiración que condense todo un cúmulo general de reclamaciones frustradas y no canalizadas por las instituciones.

El léxico de la cita, incluso, coincide con las herramientas conceptuales que estamos empleando para analizar el populismo español. En efecto, se habla de un "horizonte" saturado por todas las demandas y reclamaciones que han sido dejadas de lado por los cauces de representación y acción políticas tradicionales. Por ello, en un escenario de crisis y fragmentación de los actores sociales, urge la reagrupación de amplias capas de la población, una "construcción colectiva", en sus términos. Resulta sintomático, de hecho, que la idea que este teórico tiene del populismo sea la de una "lógica de construcción de lo político" (2017), porque manifiesta de manera expresa la necesidad implícita en todos los conceptos de acción de llevar a cabo una reestructuración semántica y práctica de las relaciones sociales ofreciendo nuevos relatos con expectativas capaces de renovar un espacio de experiencia en declive.

Resulta también igualmente revelador que la articulación de los grupos sociales se realice de un modo totalmente novedoso respecto a otros tipos de práctica política, dada la necesidad de reordenar las estructuras de acción que implica el populismo español. Nos referimos, por ejemplo, a uno de los rasgos que expusimos en las primeras páginas de este artículo: la polarización extrema del escenario político. No basta con aludir a una "clase" o tampoco a unos u otros determinados grupos sociales, sino en poner en marcha una lógica del antagonismo que reduzca la tensión de lo político a dos polos: un "ellos" y un "nosotros". Es, claro está, una "construcción teórica" que no puede neutralizar la pluralidad efectiva de los diferentes sectores y grupos que componen la sociedad civil (en este sentido "populismo" opera, en cuanto idea-límite, como "totalitarismo"), pero pretende funcionar para reorganizar las fuerzas sociales y plantear una nueva visión de las relaciones políticas, como antes hicieran otros conceptos de acción (fascismo, comunismo, republicanismo...). Buena prueba de ello es que el mismo Errejón (2016) haya insistido en la idea de "transversalidad" como una operación que busca "vertebrar a sectores sociales muy diferentes para construir un proyecto de país que no deje a nadie atrás"14.

Si volvemos la vista a los manifiestos de las asociaciones que impulsaron el 15-M, como ya hicimos antes, y analizamos estos fenómenos en cuanto germen del populismo español, vemos que la retórica es muy similar. En el caso del texto de Juventud sin futuro vemos cómo "ellos" (el sistema financiero, la clase política en general, etc.) no son parte de la solución, mientras que el "nosotros"

${ }^{14}$ El subrayado es propio.

Araucaria. Revista Iberoamericana de Filosofia, Política, Humanidades y Relaciones Internacionales, año $22, \mathrm{n}^{\circ} 44$. Segundo semestre de 2020. Pp. 155-176. ISSN 1575-6823 e-ISSN 2340-2199 https://dx.doi.org/10.12795/araucaria.2020.i44.07 
(un grupo de jóvenes descontentos que escriben el manifiesto pero que extienden sus demandas al conjunto de la sociedad) se enfrentan en el escenario político. También observamos en el manifiesto de Democracia real ya la ambición de erigirse como un sujeto político que, superando las eventuales diferencias, consiga agrupar a ese "99\%" compuesto por "personas normales y corrientes [...] Gente que trabaja duro todos los días para vivir y dar un futuro mejor a los que nos rodean". De este modo, la plataforma sostiene la transversalidad de su alcance, capaz de implicar a todo "ciudadano de a pie" capaz de "indignarse": no es el discurso de una conciencia de clase, por ejemplo, el que protagoniza el documento, lo que podría excluir, inmediatamente, a otros sectores sociales, sino que todo ciudadano está virtualmente llamado a identificarse con el sujeto político propuesto por el manifiesto.

\subsection{Populismo: como indicador y factor de cambio}

Espacio de experiencia, horizonte de expectativas, conceptos de movimiento y de acción son algunas de las herramientas de la historia conceptual de Koselleck que nos han permitido analizar la idea de populismo desde un punto de vista filosófico. A continuación quisiéramos completar este breve estudio añadiendo un par de ideas que también le debemos al teórico de la historia alemán: la peculiar ambivalencia de los conceptos como indicadores y factores de cambio.

El populismo, como concepto de acción, se caracteriza por una determinada relación entre el espacio de experiencia y el horizonte de expectativas, pero también, como hemos señalado, por articular a un determinado grupo de personas que se reconocen en él y se consideran en posición de actuar. Es precisamente este hecho según el cual el concepto resulta tanto una estructura desde la que hacer un diagnóstico del tiempo presente como un impulso para la praxis lo que le imprime su doble peculiaridad: "un concepto [...] no sólo indica unidades de acción: también las acuña y las crea. No es sólo un indicador, sino también un factor de grupos políticos o sociales" (Koselleck, 1993: 206) ${ }^{15}$.

Como indicador, los conceptos agrupan una serie de fenómenos (políticos, sociales, etc...) de los que sirven como insignia a la vez que tratan de interpretarlos de acuerdo con sus fines particulares. De este modo, el cambio social queda debidamente recogido a través de determinados conceptos, capaces de atrapar el contexto socio-político del que surgen. Determinadas circunstancias sociales

\footnotetext{
${ }_{15}$ Por ejemplo, el partido político Podemos puede ser analizado desde el punto de vista de su trayectoria empírica como "populista", sin embargo, también en el plano de su autoconcepción, es decir, de las ideas, creencias y teorías que comparten los propios agentes sociales inmersos en el partido, puede hablarse de "populismo", dada su estrecha relación con las tesis de Laclau y Mouffe. La forma más explícita de esta tensión la ha explicitado su líder al preguntarse si Podemos tenía que “seguir siendo populista o no". Véase Iglesias (2016).
} 
y movimientos históricos de mayor o menor recorrido quedan cristalizados en los conceptos, que funcionan como indicadores de un momento específico. Es el caso del populismo español y algunas de las nociones que ha acuñado, como "crisis de régimen". No se trata, como en el escenario político previo a la irrupción del populismo, de la adhesión a unas u otras identidades ideológicas y del conjunto de ciertos diagnósticos sociales dentro de un marco irrebasable, sino que el populismo funciona como indicador de una quiebra en la historia nacional que, desde su perspectiva, abre un tiempo completamente nuevo: él mismo solo es posible en una situación de crisis que haya fragmentado todo lo que antes era sostenido por un consenso. La crisis económica, la frustración por el sistema neoliberal o las dificultades institucionales que ha atravesado la España democrática (bipartidismo, corrupción, etc...) serían algunas de las circunstancias que quedan señaladas por el populismo. De ahí que su teórico Errejón (2015) pueda estar en posición de afirmar lo siguiente:

España atraviesa una crisis de régimen que es una fractura de los consensos y una desarticulación de las identidades tradicionales, y existen las condiciones para que un discurso populista de izquierdas, que no se ubique en el reparto simbólico de posiciones del régimen, sino que busque crear otra dicotomía, articule una voluntad política con posibilidad de ser mayoritaria.

En semejante situación de crisis donde se deshacen los viejos consensos y las identidades se fragmentan, el populismo español reestructura sus fuerzas sociales y guía la acción política de un modo como solo lo pueden hacer los conceptos indicadores de una profunda transformación-social, económica, ideológica-y, a su vez, se convierte en el depositario de una serie de cambios sociales que pretenden ser realizados. Esta manera inevitablemente ambivalente en que el populismo remite a la necesidad de unas modificaciones estructurales es, en realidad, significativa en la medida en que comparte con otras épocas históricas la singularidad de que siempre suceden en tiempos de mutaciones sociales y semánticas. Especialmente si tenemos en cuenta la siguiente consideración de Koselleck (1993: 111):

La lucha semántica por definir posiciones políticas o sociales y en virtud de esas definiciones mantener el orden o imponerlo corresponde, desde luego, a todas las épocas de crisis que conocemos por fuentes escritas. Desde la Revolución francesa, esta lucha se ha agudizado y se ha modificado estructuralmente: los conceptos ya no sirven solamente para concebir los hechos de tal o cual manera, sino que se proyectan hacia el futuro.

Nos queda, finalmente, hacer una mención a la idea de populismo como factor de cambio. Y es que si es cierto que los conceptos indican determinadas circunstancias socio-políticas, también lo es que animan y realizan su transformación. Como señala 
Koselleck (1993: 118), "con cada concepto se establecen determinados horizontes, pero también límites para la experiencia posible y para la teoría concebible". En el caso del populismo, hemos visto cómo, más allá del espacio de experiencia que se quiere negar ("régimen del 78"), no cuenta todavía con un acopio sólido de experiencias más que a través de diferentes situaciones concretas, por otra parte nada despreciables, como el gobierno municipal de algunas de las principales ciudades del país (como Madrid o Barcelona). Sin embargo, ya vimos cómo los conceptos de movimiento y acción no necesitan partir de un espacio de experiencia ya preexistente, sino que precisamente se abren paso en una realidad sociopolítica implantando lo que hasta entonces solo tiene realidad en los planes, intenciones y programas de sus agentes.

En este sentido, el hecho de que en el partido político exista un secretario de Análisis Estratégico y Cambio Político resulta sintomático, pues pone el foco de atención en el componente transformador, de cambio, que implican sus políticas. También, recordamos, se denomina a los ayuntamientos gobernados por Podemos "del cambio" y se llevan a cabo campañas electorales bajo el rótulo de "Rutas del Cambio". Sin embargo este cambio existe solo representado, pero no ejercido, pues hasta la fecha no se ha dado la oportunidad de que exista un gobierno populista en el país ${ }^{16}$. Sin embargo, esto no minimiza su éxito como factor de cambio, pues difícilmente podría negarse que el escenario político español y la semántica social de nuestro tiempo, lo que incluye, por cierto, a los debates intelectuales y filosóficos, ha quedado considerablemente transformada desde la irrupción del populismo español. Lo sabe Errejón (2016) cuando afirma que el éxito de Podemos "no sólo se refleja en sus resultados electorales, sino en que ha cambiado ya gran parte de la disputa política en España [...] renovando el lenguaje y otorgando una importancia central a la batalla por el relato".

Cuestión que merecería un análisis aparte es si esa renovación del lenguaje ha adquirido una valencia positiva o negativa, articulando una confusa y nada inocente "jerga de la autenticidad" que, en cuanto velo ideológico, ha sometido a los principales conceptos de la vida social y política a una intensa erosión y deformación que ha introducido a la izquierda política nacional en un oscuro callejón sin salida. Pero esto ya debería ser motivo de otro estudio.

${ }_{16}$ Merece la pena recordar, dado el vaciamiento político al que el populismo español somete a la noción de "cambio", unas palabras de Adorno (2009: 42) a propósito de las experiencias fascistas: "El movimiento es concebido como un fin en sí mismo, al igual que los nazis, que siempre hicieron un fetiche del término Bewegung, sin señalar hacia dónde se dirigía ese Bewegung. «Este gran movimiento», la glorificación de la acción, de algo en curso, borra y sustituye a la vez el propósito del movimiento [...] El movimiento es presentado como un valor per se, porque se entiende que el movimiento implica [...] una exhibición del propio poder de uno". 


\section{Referencias bibliográficas:}

Adorno, Th. W., Escritos Sociológicos II, vol. 1, Akal, Madrid, 2009.

Boltanski, L. y Chapiello È., El nuevo espíritu del capitalismo, Akal, Madrid, 2002.

Bueno Romero, G. A., "El populismo como concepto en América Latina y en Colombia", Estudios Políticos 42 (Instituto de Estudios Políticos, Universidad de Antioquía): 112-137, 2013.

Dean, J., Crowds and Party, Verso, Londres, 2018.

del Palacio Martín, J., "El populismo en Italia: el berlusconismo y su legado".

En A. Rivero Rodríguez, J. Zarzalejos y J. del Palacio Martín (coord.), Geografía del populismo (pp. 234-247), Tecnos, Madrid, 2017.

Errejón, Í., "Desplegar las velas: un Podemos para gobernar". Recuperado de: estaticos.elmundo.es/documentos/2017/01/13/Errejon.pdf, 2017.

Errejón, Í., "Errejón recuerda que Podemos ha llegado hasta aquí sin pedir el carné a nadie". Recuperado de: https://www.eldiario.es/politica/Errejonrecuerda-Podemos-llegado-nadie 0 584092300.html, 2016.

Errejón, Í., "Podemos a mitad de camino". Recuperado de: http://ctxt.es/ es/20160420/Firmas/5562/Podemos-transformacion-identidad-podercambio-Tribunas-y-Debates.htm, 2016.

Europa Press (Agencia), "Podemos defiende «un discurso populista de izquierda» y que sin el aprendizaje latinoamericano no habría tenido éxito". Recuperado de: http://www.europapress.es/nacional/noticia-podemosdefiende-discurso-populista-izquierda-aprendizaje-latinoamericano-nohabria-tenido-exito-20140713113442.html, 2015.

Formenti, C., La variante populista, DeriveApprodi, Roma, 2016.

Fukuyama, F., The End of History and the Last Man, Free Press, Nueva York, 1992.

Gómez Ramos, A., "Koselleck y la Begriffgeshichte. Cuando el lenguaje se corta con la historia", introducción a R. Koselleck: historia/Historia, Trotta, Madrid, 2004.

Í. Errejón, "La construcción de un sujeto popular", Revista Teknokultura 12(1): 39-53, 2015.

Iglesias, P. "El debate que temenos es si Podemos tiene que seguir siendo populista o no". Recuperado de: https://www.eldiario.es/politica/PabloIglesias-debate-Podemos-populista 0 566244376.html, 2016.

Jespersen, B., "What Is Populism?”, Organon F, 24(2): 245-254, 2017.

Koselleck, R., Estudios sobre semántica y pragmática del lenguaje político y social, Trotta, Madrid, 2012.

Koselleck, R., Futuro pasado, Paidós, Barcelona, 1993.

Laclau, E., La razón populista, FCE, México, 2015. 
Lukács, G., El asalto a la razón. La trayectoria del irracionalismo desde Schelling hasta Hitler, Grijalbo, Barcelona, 1976.

Monedero, J. C., "Gramsci en Sálvame”. Acceso digital: https://www.elmundo. es/opinion/2014/09/18/541b2faeca4741d0048b456c.html [artículo de Raúl del Pozo], 2015.

Mouffe, C., For a Left Populism, Verso, Londres, 2018.

Savarino, F., "Populismo: perspectivas europeas y latinoamericanas", Espiral (Guadalajara) 13(37): 77-94, 2006.

Sciortino, R., I dieci anni che sconvolsero il mondo. Crisi globale e geopolitica dei neopopulismi, Asterios, Trieste, 2019.

Soto Carrasco, D., "Podemos O La irrupción Plebeya: Nota bibliográfica", Sociología Histórica 5: 547-63, https://revistas.um.es/sh/ article/view/246741, 2015.

Villacañas, J. L., Populismo, La Huerta Grande, Madrid, 2015.

Weber, M. Economía y Sociedad, FCE, México, 1994.

Wiles, P. "Un síndrome, no una doctrina: algunas tesis elementales sobre el populismo". En G. Ionescu y E. Gellner (comps.), Populismo. Sus significados en características nacionales (pp. 203-220), Amorrortu, Buenos Aires, 1970.

Žižek, S., “Against the Populist Temptation", Critical Inquiry 32(3): 551-574, 2006. 